\title{
Ground-based assessment of JAXA mouse habitat cage unit by mouse phenotypic studies
}

\author{
Miki SHIMBO $^{1-3)}$, Takashi KUDO ${ }^{1,2,4)}$, Michito HAMADA ${ }^{1,2,4)}$, Hyojung JEON ${ }^{1-3)}$, \\ Yuki IMAMURA ${ }^{2,5)}$, Keigo ASANO ${ }^{2,5)}$, Risa OKADA ${ }^{1,2)}$, Yuki TSUNAKAWA ${ }^{2,6)}$, Seiya MIZUNO ${ }^{4,7)}$, \\ Ken-ichi YAGAMI ${ }^{1,4,7)}$, Chihiro ISHIKAWA ${ }^{8,9)}$, Haiyan LI ${ }^{8,9)}$, Takashi SHIGA ${ }^{1,8)}$, Junji ISHIDA ${ }^{1,10,11)}$, \\ Juri HAMADA ${ }^{10,11)}$, Kazuya MURATA ${ }^{11)}$, Tomohiro ISHIMARU ${ }^{10)}$, Misuzu HASHIMOTO ${ }^{6}$, \\ Akiyoshi FUKAMIZU ${ }^{1,10,11)}$, Mutsumi YAMANE ${ }^{1,12)}$, Masahito IKAWA ${ }^{1,12)}$, Hironobu MORITA ${ }^{1,13)}$, \\ Masahiro SHINOHARA $^{1,14)}$, Hiroshi ASAHARA ${ }^{1,14)}$, Taishin AKIYAMA ${ }^{1,15)}$, Nobuko AKIYAMA ${ }^{15)}$, \\ Hiroki SASANUMA ${ }^{16)}$, Nobuaki YOSHIDA ${ }^{1,16)}$, Rui ZHOU ${ }^{17,18)}$, Ying-Ying WANG $^{17)}$, Taito ITO $^{10,17)}$, \\ Yuko KOKUBU ${ }^{10,17)}$, Taka-aki K. NOGUCHI ${ }^{10,17)}$, Hisako ISHIMINE ${ }^{17)}$, Akira KURISAKI ${ }^{1,10,17)}$, \\ Dai SHIBA ${ }^{1,19)}$, Hiroyasu MIZUNO ${ }^{1,19)}$, Masaki SHIRAKAWA ${ }^{1,19)}$, Naoki ITO ${ }^{20)}$, \\ Shin'ichi TAKEDA ${ }^{20)}$, and Satoru TAKAHASHI ${ }^{1,2,4)}$
}

1) Mouse Epigenetics Project, ISS/Kibo experiment, JAXA, Japan

2) Department of Anatomy and Embryology, Faculty of Medicine, University of Tsukuba, Japan

3) Doctoral Program in Biomedical Sciences, Graduate School of Comprehensive Human Sciences, University of Tsukuba, Japan

4) Laboratory Animal Resource Center, University of Tsukuba, Japan

5) Master's Program in Medical Sciences, Graduate School of Comprehensive Human Sciences, University of Tsukuba, Japan

6) Ph.D. Program in Human Biology, School of Integrative and Global Majors, University of Tsukuba, Japan

7) Department of Laboratory Animal Science, Faculty of Medicine, University of Tsukuba, Japan

8) Department of Neurobiology, Faculty of Medicine, University of Tsukuba, Japan

9) Doctoral Program in Kansei, Behavioral and Brain Sciences, Graduate School of Comprehensive Human Sciences, University of Tsukuba, Japan

10) Graduate School of Life and Environmental Sciences, University of Tsukuba, Japan

11) Life Science Center, Tsukuba Advanced Research Alliance (TARA), University of Tsukuba, Tsukuba, Ibaraki 305-8575, Japan

12) Research Institute for Microbial Diseases, Osaka University, Suita, Japan

13) Department of Physiology, Gifu University Graduate School of Medicine, Yanagido, Gifu 501-1194, Japan

14) Department of Systems BioMedicine, Graduate School of Medical and Dental Sciences, Tokyo Medical and Dental University, Bunkyo-ku, Tokyo, 113-8510, Japan

15) Division of Cellular and Molecular Biology, The Institute of Medical Science, The University of Tokyo, Tokyo 108-8639, Japan

16) Laboratory of Developmental Genetics, Center for Experimental Medicine and Systems Biology, The Institute of Medical Sciences, The University of Tokyo, Minato-Ku, Tokyo 108-8639, Japan

17) Biotechnology Research Institute for Drug Discovery, National Institute of Advanced Industrial Science and Technology (AIST), Tsukuba Central 4-1-3106, Tsukuba, Ibaraki 305-8562, Japan

18) Key Laboratory of Medical Electrophysiology, Ministry of Education, Collaborative Innovation Center for Prevention and Treatment of Cardiovascular Disease/Institute of Cardiovascular Research, Sichuan Medical University, Luzhou, Sichuan, P.R. China

19) JEM Utilization Center, Human Spaceflight Technology Directorate, JAXA, Tsukuba, Ibaraki 305-8505, Japan

20) Department of Molecular Therapy, National Institute of Neuroscience, National Center of Neurology and Psychiatry, Kodaira, Tokyo, 187-8502, Japan

(Received 5 August 2015 / Accepted 1 January 2016 / Published online in J-STAGE 28 January 2016)

Adress corresponding: T. Kudo, Department of Anatomy and Embryology, Faculty of Medicine, University of Tsukuba, 1-1-1 Tennodai, Tsukuba, Ibaraki, 305-8575, Japan / S. Takahashi, Department of Anatomy and Embryology, Faculty of Medicine, University of Tsukuba, 1-1-1 Tennodai, Tsukuba, Ibaraki, 305-8575, Japan

Supplementary tables: refer to J-STAGE: https://www.jstage.jst.go.jp/browse/expanim

(C2016 Japanese Association for Laboratory Animal Science 


\begin{abstract}
The Japan Aerospace Exploration Agency developed the mouse Habitat Cage Unit (HCU) for installation in the Cell Biology Experiment Facility (CBEF) onboard the Japanese Experimental Module ("Kibo") on the International Space Station. The CBEF provides "space-based controls" by generating artificial gravity in the HCU through a centrifuge, enabling a comparison of the biological consequences of microgravity and artificial gravity of $1 \mathrm{~g}$ on mice housed in space. Therefore, prior to the space experiment, a ground-based study to validate the habitability of the $\mathrm{HCU}$ is necessary to conduct space experiments using the $\mathrm{HCU}$ in the CBEF. Here, we investigated the ground-based effect of a 32-day housing period in the HCU breadboard model on male mice in comparison with the control cage mice. Morphology of skeletal muscle, the thymus, heart, and kidney, and the sperm function showed no critical abnormalities between the control mice and HCU mice. Slight but significant changes caused by the HCU itself were observed, including decreased body weight, increased weights of the thymus and gastrocnemius, reduced thickness of cortical bone of the femur, and several gene expressions from 11 tissues. Results suggest that the HCU provides acceptable conditions for mouse phenotypic analysis using CBEF in space, as long as its characteristic features are considered. Thus, the $\mathrm{HCU}$ is a feasible device for future space experiments.
\end{abstract}

Key words: habitat cage unit, microgravity, mouse, spaceflight

\section{Introduction}

As sensing and adapting to a changing environment is key for any organism's survival, the constant mechanical stimulus of gravity is the one prominent factor that most organisms on Earth have shared through evolution. In order to elucidate how mammals respond to gravity, outer space experiments utilizing mice are among the most essential studies, and require specialized habitats applicable to the space environment. Historically, the Animal Enclosure Module (AEM) had flown since its maiden flight in 1983, carrying mice and rats on over 20 Space Shuttle missions [15]. The biosatellites, launching animals into the orbit and returning to Earth since 1957, cannot be overseen for their contribution to space science, advancing to the recent Russian Bion-M1 [21]. Today, the Japanese Experimental Module ("Kibo") onboard the International Space Station (ISS) is in the spotlight, as this laboratory allows longer-term space study due to its permanently functioning capability. Research utilizing Kibo began in 2008, with the Italian Mice Drawer System being used successfully in a mouse space study [2]. Such studies have brought valuable insights about the spaceflight effects on mice; however, one drawback in such studies comparing space-housed mice to ground-housed mice limits the borders regarding gravitational biology. As various conditions differ between the ground and space environments including cosmic radiation, microbial environment, and lack of convection, setting ground-housed mice as a control group prevents clear identification of the microgravity impacts on such mice. As a solution, the Japan Aerospace Exploration Agency (JAXA) developed the Cell Biology Experiment Facility (CBEF) [30], equipped with sections providing microgravity and artificial gravity of $1 \mathrm{~g}$. The artificial gravity of $1 \mathrm{~g}$ generated by a short-arm centrifuge enables space-based control, where all conditions are equalized apart from the gravitational difference. To date, the CBEF has housed numerous organisms including cell lines, nematode, aquatic organisms, and plants, but not mice. In this study, we developed the mouse Habitat Cage Unit (HCU) for installation in the CBEF. By utilizing $\mathrm{HCU}$ cages for all variable gravity conditions, including microgravity, artificial gravity of $1 \mathrm{~g}$ generated by CBEF in space, and ground-based $1 \mathrm{~g}$, it defines the impacts of microgravity and the space environment for future studies. Although there have been concerns over the large Coriolis force and gravitational gradient inside the cage generated by the short-arm centrifuge of CBEF, we recently reported that both concerns cause no biological consequences on mice [17]. In order to proceed with further mouse studies in space, the characterization of the HCU must be carefully defined by comparing with control cages at ground level, as a nonstandard habitat may affect mice regardless of gravitational differences, like the AEM [16]. Therefore, prior to the space experiments, molecular, histological, and physiological examinations of the whole body of mice were conducted to evaluate HCU habitability. 
Table 1. Comparison of major features of cages in this study

\begin{tabular}{lcc}
\multicolumn{1}{c}{ Cage } & HCU & Control cage \\
\hline $\begin{array}{l}\text { Duration } \\
\text { Mice }\end{array}$ & \multicolumn{2}{c}{ C57BL/6J, male, 8-week old, $\mathrm{n}=6$} \\
Floor area & $101 \mathrm{~cm}^{2}$ & $552 \mathrm{~cm}^{2}$ \\
Capacity & $560 \mathrm{~cm}^{3}$ & $7,256 \mathrm{~cm}^{3}$ \\
Food shape & Special food bar & Solid pellets $(12 \mathrm{~mm} \Phi)$ \\
Bedding & No & Yes \\
Airflow & $0.2 \mathrm{~m} / \mathrm{sec}$ & No \\
Drinking water & \multicolumn{2}{c}{ Tap water } \\
\hline
\end{tabular}

\section{Materials and Methods}

\section{Animals}

Mice were maintained under specific pathogen-free conditions in a Laboratory Animal Resource Center at the University of Tsukuba. All experiments were approved by the institutional animal care and use committees of the University of Tsukuba (No. 14-235) and JAXA (JAXA IACUC protocol No. 014-008), and conducted according to related guidelines and applicable laws in Japan. Seven-week old C57BL/6J male mice were purchased from Charles River Laboratories International, Inc. (Japan). They were acclimatized to the environment for one week in HEPA filtered disposable cages (Inocage; Oriental Giken, Tokyo, Japan). Six mice were individually transported and housed in the HCUs for 32 days. Six other control mice remained in the Inocages as the control group. Table 1 summarizes the comparison between control cages and the HCUs. The floor area and volume of the cage area in the HCU $\left(101 \mathrm{~cm}^{2}\right.$, $560 \mathrm{~cm}^{3}$ ) is smaller than that of the control cage (Inocage, $\left.552 \mathrm{~cm}^{2}, 7,256 \mathrm{~cm}^{3}\right)$. The floor area and volume of the cages were designed according to the Guide for the Care and Use of Laboratory Animals (National Research Council 2011), having been approved by the institutions concerned, including the University of Tsukuba and JAXA. Approval from the National Aeronautics and Space Administration (NASA) must be obtained for further references and processes. The bedding material consisted of paper chips (ALPHA-DRI; Shepherd Specialty Papers Inc., Watertown, MA, USA) in the control cages, but was not used in the HCU. As in the conventional mouse cages, the internal materials of the walls and floor of the $\mathrm{HCU}$ are made of polycarbonate. Almost all internal parts of HCU can be dismounted and sterilized by using an autoclave or ethylene oxide gas. Both control cages and HCUs were placed in an air-condi- tioned room (average temperature; $24.1{ }^{\circ} \mathrm{C}$, average relative humidity; $42.8 \% \mathrm{RH}$ ) with a $12: 12$-h light-dark cycle. The average temperature inside the HCU was $25.7^{\circ} \mathrm{C}$ and average relative humidity was $41.3 \% \mathrm{RH}$. Airflow by fan $(0.2 \mathrm{~m} / \mathrm{sec})$ was always supplied inside the HCU for maintaining the same conditions as in the actual space experiment. The mice were fed CRF-1 (Oriental Yeast Co., Ltd., Tokyo, Japan) and given water $a d$ libitum. The drinking water was autoclaved tap water containing iodine $(0.2 \mathrm{mg} / \mathrm{l})$. Feeder cartridges and water bottles were replaced once a week, and cage refreshing was not done in the HCU. After both mouse groups were housed for 32 days, we checked the health condition of the mice and measured their body weights. Motor function was estimated using the rotarod test (47600, Bioresearch Center, Nagoya, Japan) as previously described [17]. All mice were euthanized by inhaling lethal doses of isoflurane, and then subjected to dissection for collecting tissue samples.

\section{Hematologic analysis of peripheral blood}

Peripheral blood samples were collected from the inferior vena cava of anesthetized mice by using a syringe containing EDTA-2K solution. Blood count was determined with an automated hemocytometer (Nihon Kohden, Tokyo, Japan). Blood samples were smeared onto microscope slides and stained with May-GrünwaldGiemsa stain, and then photographed with a BIOREVO BZ-9000 microscope (Keyence, Osaka, Japan).

\section{Immunohistochemistry}

Immunohistochemical analysis on the thymus [1], heart, kidney [9], and skeletal muscle [11] was conducted as previously described. Supplementary Table 1 lists the primary antibodies used. The heart muscle sections were stained with Phalloidin-TRITC (Sigma, St. Louis, MO, USA). Immunodetection was performed using Alexa Fluor conjugated secondary antibodies (Molecular Probes). These sections were observed with a BIOREVO BZ-9000 microscope (Keyence). The numbers of immunoreactive muscle fiber and cross-sectional areas were measured using Dynamic Cell Count BZH1C software (Keyence).

\section{Enzyme-Linked ImmunoSorbent Assay (ELISA)}

ELISA assays were performed as previously described with some modifications [19]. In brief, flat-bottom 96well plates (NUNC) were coated with rat anti-mouse 
IgM, IgG1, IgG3 and IgA antibodies (Southern Biotechnology, Birmingham, AL, USA) and blocked with 3\% BSA in PBS. To generate standard curves, isotype-specific affinity-purified mouse antibodies (Southern Biotechnology) were used. Serially diluted standards and plasma samples were then loaded to assigned wells, and then incubated for $1 \mathrm{~h}$ at room temperature. Bound antibodies were detected by HRP-conjugated goat antimouse isotype-specific antibodies (Southern Biotechnology), followed by the addition of SureBlue ${ }^{\mathrm{TM}} \mathrm{TMB}$ Microwell Peroxidase Substrate (KPL, Gaithersburg, MD, USA). Absorbance at $450 \mathrm{~nm}$ was measured using an iMark microplate reader (BioRad, Hercules, CA, USA).

\section{Quantitative RT-PCR}

Total RNAs were isolated from various tissue using the RNeasy Mini Kit (QIAGEN, Venlo, Netherlands) or ISOGEN solution (Nippon Gene, Tokyo, Japan), and cDNA templates were synthesized from the total RNA with the QuantiTect Reverse Transcription Kit (QIAGEN). PCR was carried out using the TP850 Thermal Cycler Dice Real Time System (Takara, Shiga, Japan) with SYBR Premix Ex Taq II (Takara). Supplementary Table 5 lists the primer sequences. The relative amount of each gene was normalized to the amount of the Gap$d h, H p r t$, or Tbp transcript in the same cDNA.

\section{MicroCT analysis}

After skeletal muscles were carefully removed from the mouse hindlimbs, femurs were fixed in $70 \%$ ethanol and subjected to microcomputed tomography (microCT) analysis as previously described [24]. MicroCT scanning was performed using a ScanXmate-A100S Scanner (Comscantechno, Yokohama, Japan), and the three-dimensional microstructure of the metaphysical region in the femur was analyzed using TRI/3D-BON software (RATOC, Tokyo, Japan).

\section{Sperm motility}

Spermatozoa collected from cauda epididymis were frozen as previously described [27]. After thawing, spermatozoa were dispersed into TYH in vitro fertilization medium and sperm motility was observed under a phase contrast microscope. Sperm parameters were measured with a computer-assisted sperm analysis system (CEROS-II; Hamilton Thorne, Beverly, MA, USA) as per the manufacturer's instructions.

\section{Statistical analysis}

Statistical analyses were conducted using the F-test followed by an unpaired Student's $t$ test or Welch's test. $P$ values are provided in the legend of the figures, marked with asterisks in the figures and tables. Real time PCR data were evaluated using the Mann-Whitney test.

\section{Results and Discussion}

\section{The JAXA mouse Habitat Cage Unit (HCU)}

Mice are scheduled to stay in the HCU on Kibo for a few months and then return to Earth alive. In order to conduct a comparison experiment entailing microgravity and artificial gravity of $1 \mathrm{~g}$, the $\mathrm{HCU}$ is shaped in a hollow cylinder section to be installed in the CBEF (Figs. $1 \mathrm{~A}$ and $\mathrm{B})$. The microgravity and artificial gravity of 1 $g$ sections each contain six HCUs. The HCU is designed for individual housing, thus offering a great advantage in enabling the housing of male mice in space. In previous studies, mouse habitat units were designed for group housing, restricting them to female mice experiments, as the group housing of male mice induces fight responses. In order to continuously monitor each condition, the $\mathrm{HCU}$ is composed of a cage equipped with a $\mathrm{CO}_{2}$ sensor, $\mathrm{NH}_{3}$ sensor, and a temperature/humidity sensor. To visually check the health condition of mice and the cage conditions, cameras are installed in each HCU cage for the continuous monitoring and recording of mice behavior during the entire 32-day period (Figs. 1C and E). A fully operational self-feeder unit, waste-collecting equipment, two self-watering units (A1400; Edstrom Japan, Tokyo, Japan), and a ventilation fan were also installed and are functional at any given time. For all disposals into the waste-collecting equipment, many circular holes (5 mm in diameter, Fig. 1C) are left open in a regular fashion at the bottom of the HCU cage, with the assistance of a ventilation fan having a regulated noise level of $60 \mathrm{~dB}$. The intensity of the periodically functioning LED lights built into the HCU is approximately 50 lux. The CRF-1 food bars loaded in the selffeeder unit with stainless guard bars $(1 \mathrm{~mm}$ in diameter, Fig. 1D) provide food when needed. While containing the same ingredients, the food bar is larger than the standard CRF-1 pellet. These features allow minimum effort to constantly provide food, as ample food sources will be orderly supplied as the food is consumed. In order to confirm the possibility of contaminated drinking water, bacterial cultures for Psedomonas aeruginosa tests were 

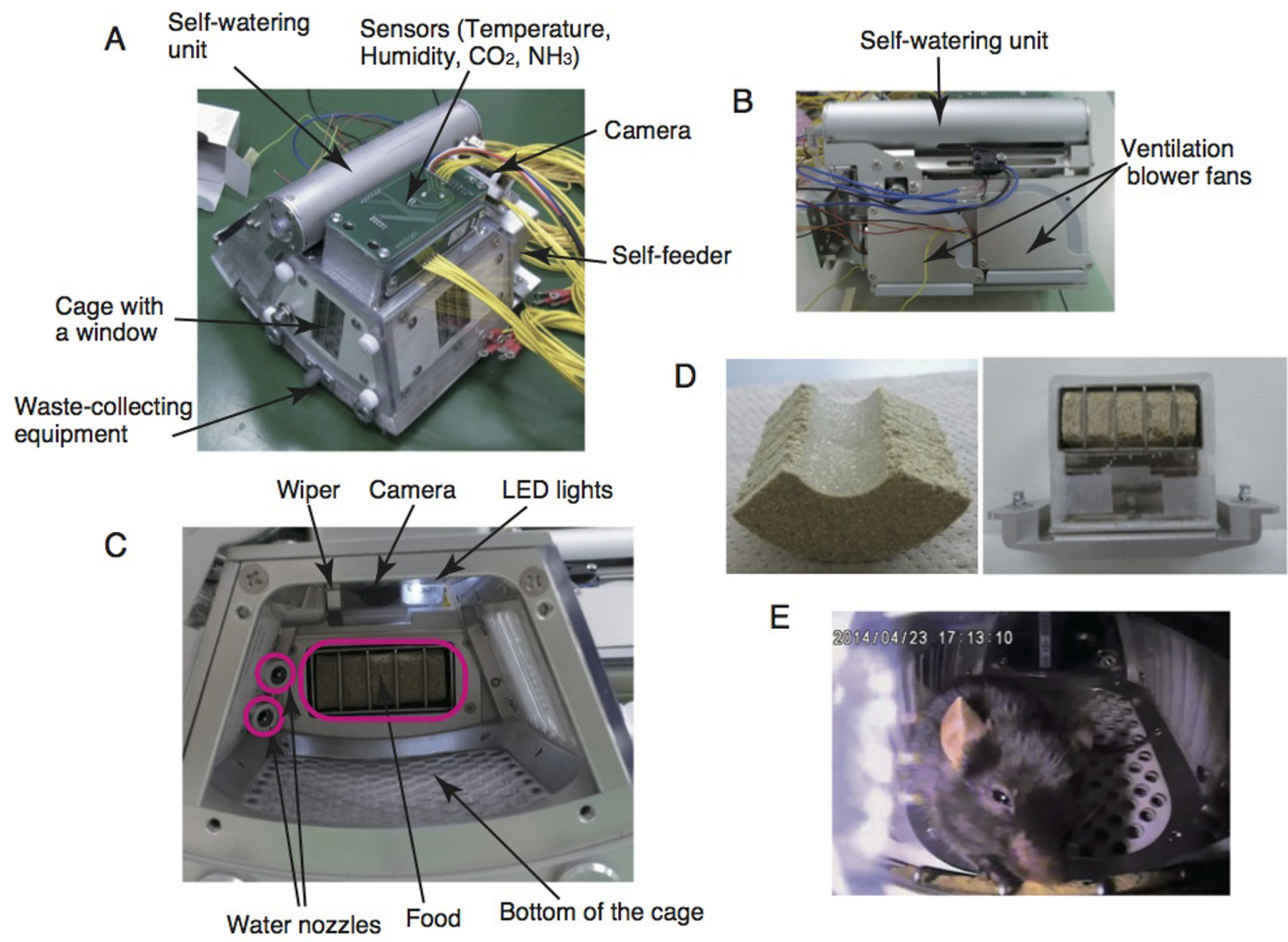

E

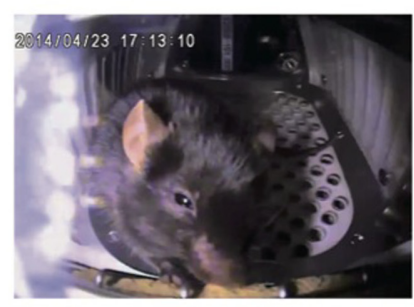

F

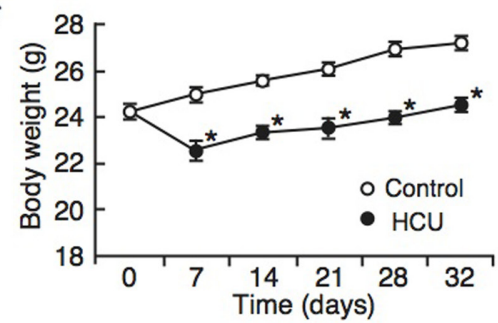

$\mathrm{H}$

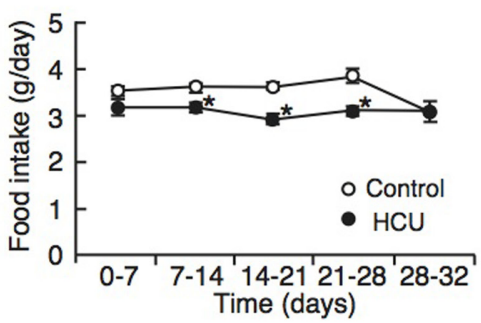

G

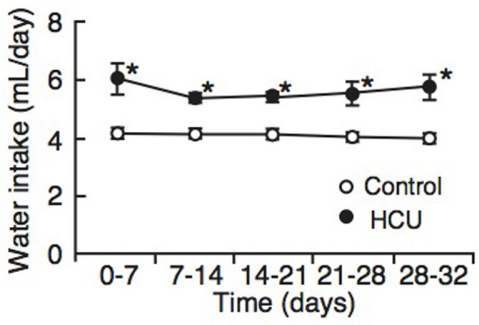

I

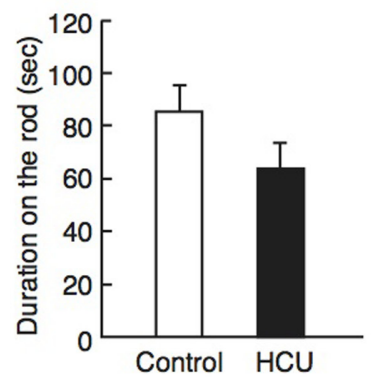

Fig. 1. Mice housed in the Habitat Cage Unit (HCU) for 32 days

(A, B) Appearance of the HCU. (C) Inside the HCU. (D) Special food bars in the feeder cartridge. (E) A mouse in the HCU cage. (F) Body weight after housing in the control cage (Inocage) and the HCU for 32 days. (G) Water consumption data. (H) Food consumption data. (I) Measured duration for which mice could maintain themselves on the rotarod in both the control and HCU groups. The testing mice were placed on the rotarod two times, with retention times being averaged. Rotation speed increased from 2 to $40 \mathrm{rpm}$ in $2 \mathrm{~min}$. All data in Figure 1 are represented as means $\pm \mathrm{SEM}$. Control; $\mathrm{n}=6$, $\mathrm{HCU} ; \mathrm{n}=6$. Open bars indicate the control group. Closed bars indicate the HCU group. Asterisks denote $P<0.01$.

performed using water remaining in the bottles, resulting in negative for the HCU group (data not shown). The average room temperature and average room relative humidity during the experiment were $24.1^{\circ} \mathrm{C}$ and $42.8 \% \mathrm{RH}$, respectively. The average temperature inside the $\mathrm{HCU}$ was $25.7^{\circ} \mathrm{C}$. The habitation environment appeared to be suitable for mouse health throughout the experiment. 
Body weight, water intake, food intake, and rotarod test

As the HCU has been designed with distinct features applicable to space experiments, a range of differences were observed in the HCU-housed mice (HCU mice) as compared to the control-cage-housed mice (control mice). While the HCU mice looked the same in appearance as the control mice by day 32 , the body weights of the HCU mice were slightly but significantly lower than those of the control mice (Fig. 1F; $27.2 \pm 0.3 \mathrm{~g}$ in the control group vs. $24.5 \pm 0.3 \mathrm{~g}$ in the HCU group). This weight loss could be a consequence of the dramatic reduction seen during the first seven days of the experiment, as the growth rate frequency of mice did not alter between the control mice and the HCU mice after seven days. When the weight loss was observed in the HCU mice, food intake showed no significant difference compared to control mice (Fig. 1H). These results suggest that habitual changes, including cage size, position of water nozzles, airflow by fan, loss of bedding materials, and especially the difficulty in adapting to unusually large-sized food, may have caused a transient weight reduction amongst the HCU mice during the first seven days. This is exemplified by the steady growth rate frequency of the HCU mice matching that of control mice for the remaining 25 days after adaptation to the changing environment (Fig. 1F). This suggests that the habitual changes induced by the HCU do not cause sustained stress to mice, and that the mice can be acclimated to the HCU within seven days of habituation. Over the 25 days after adaptation, food intake was less than that of the control mice, though meeting the control values during the last five days. The smaller cage size may be suspected, since the range in cage size could be correlating to changes in physical movement of the HCU mice. However, the relationship between the weight increase rate and food intake remains unknown. The habituation of mice given the CRF-1 food bars several days prior to launch, may eliminate the weight loss effect for future space studies. Water intake was significantly excessive among the HCU mice throughout the whole period of investigation (Fig. $1 \mathrm{G})$. C57BL/6J male mice in smaller cages were previously shown to consume or waste more food and water than mice housed in larger cages [6], which is consistent with higher water consumption by the HCU mice. In addition, the restricted volume of the HCU was thought to attract the mice toward the water nozzles, leading to water wastage mistaken as water intake. We then conducted the rotarod test to evaluate whether the $\mathrm{HCU}$ impairs motor function capability. The duration time of HCU mice on the rod decreased, though not significantly as compared with that of the control mice (Fig. 1I).

Organ weight, blood indices and immunoglobulin levels

For the effects of body weight reduction of the HCU mice, we measured organ weight and normalized it with body weight. The HCU mice showed no differences in relative spleen, heart, kidney, liver, epididymal fat, inguinal fat, mesenteric fat, testis and epididymis weights, excluding a slight increase in relative thymus weight (Supplementary Table 2). Thymic size is susceptible to various stressors [8]. Normally, stressors cause thymic involution, which is the opposite case found in this study where that the HCU mice did not receive excess stress. Certain environmental factors of the HCU may have induced thymic enlargement, though the clear mechanism remains unknown.

All blood indices in the HCU group fell within the normal range, although platelet count decreased slightly but significantly (Supplementary Table 3). Plasma immunoglobulin levels did not differ between the two groups (Supplementary Table 4). Although the clear mechanism remains to be solved, these results suggest that the HCU causes a slight change on the platelet count, and at least it shows that the HCU is not a stressful environment for housing mice, as platelets are not a sensitive indicator of stress [5].

\section{Histological analysis of thymus, heart and kidney}

The weight of the thymus in rodents has reportedly decreased [7, 20] or remained unchanged [3] in space experiments. Although the thymus weight among the HCU mice increased, there was no difference in Keratin-5 and Keratin- 8 positive epithelial cells of thymi between the HCU mice and the control mice (Fig. 2). The degree of epithelial morphology revealed no change in the HCU mice. To evaluate the effect of housing in the HCU on tissue structure, histological analyses of the heart and kidney were examined. Cardiac hypertrophy and fibrosis were not observed in the heart from the HCU mice and control mice (data not shown). In the heart, connexin43, the main gap junction protein important for cardiomyocyte function, was predominantly expressed in the sarcolemma. It has been reported that, in failing hearts, total connexin 43 expression and its localization at gap junctions were reduced [13]. In this study, immunohistochemical analysis revealed no differences in 


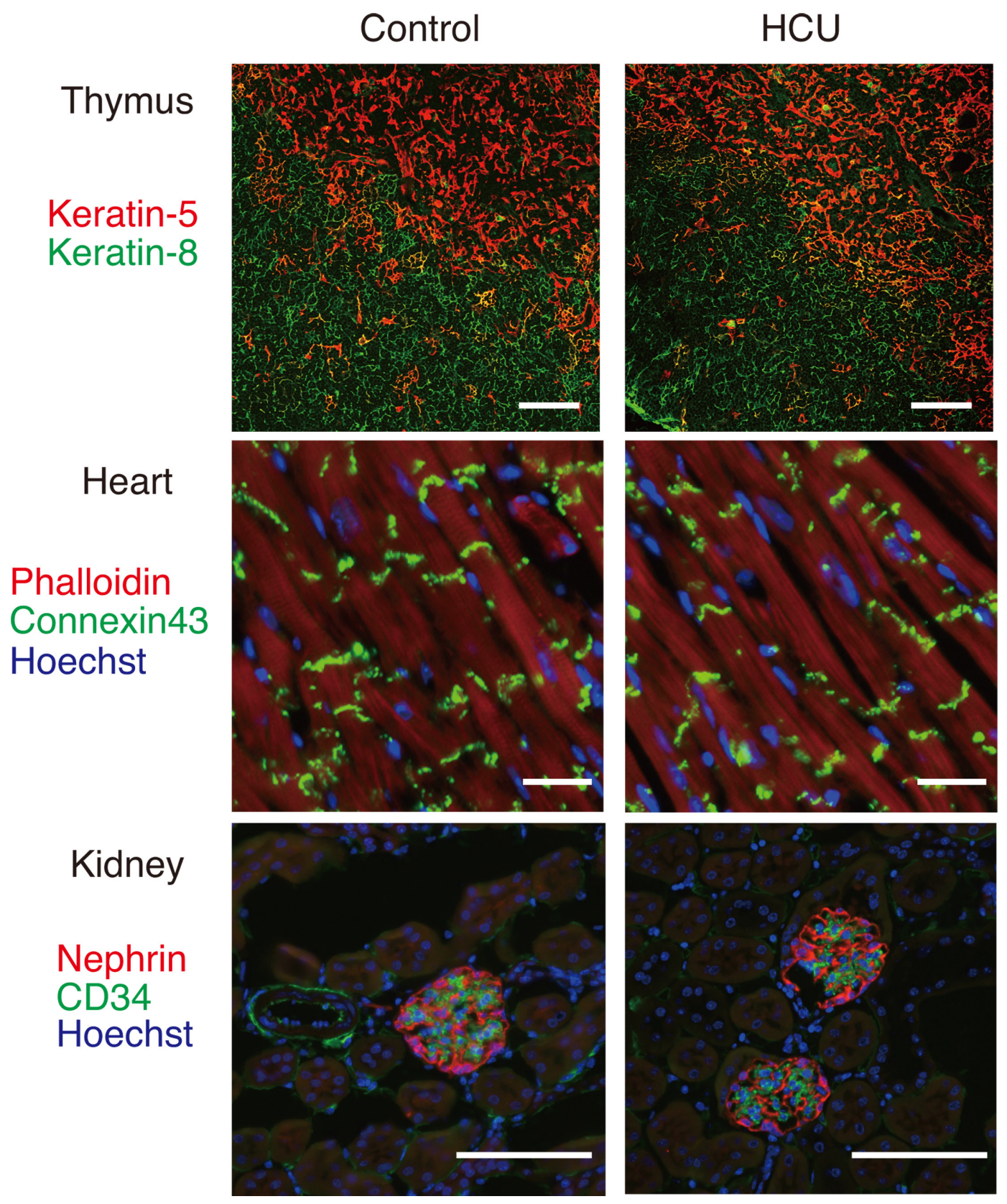

Fig. 2. Organ morphological characterization by immunohistochemical analysis

Thymic frozen sections were immunostained with a combination of anti-keratin-5 (red) and anti-keratin-8 (green) antibodies. Scale bar, $100 \mu \mathrm{m}$. Representative immunofluorescence images of the heart sections were stained with Phalloidin (red; F-actin), Connexin43 (green; gap junction), and nuclear stain Hoechst (blue). Scale bar, $100 \mu \mathrm{m}$. Kidney sections were stained with nephrin (red; podocytes in glomerulus), CD34 (green; endothelial cells), and nuclear stain Hoechst (blue). Scale bar, $100 \mu \mathrm{m}$.

connexin43 expression and localization in the heart of the HCU mice and control mice (Fig. 2). We then investigated kidney morphology, where no histological damage (including tissue injury or fibrosis) was confirmed in both groups (data not shown). In kidney disease patients, the expression of nephrin, a renal glomerulus- specific cell adhesion receptor, is known to be lowered and its localization altered. Therefore, we performed the immunostaining of nephrin and CD34, a vascular endothelial marker, in the kidney glomerulus. The expression levels of nephrin and CD34 in the HCU mice did not differ from those in the control mice (Fig. 2). These re- 
A

Sol

Pla

Gas

TA

EDL
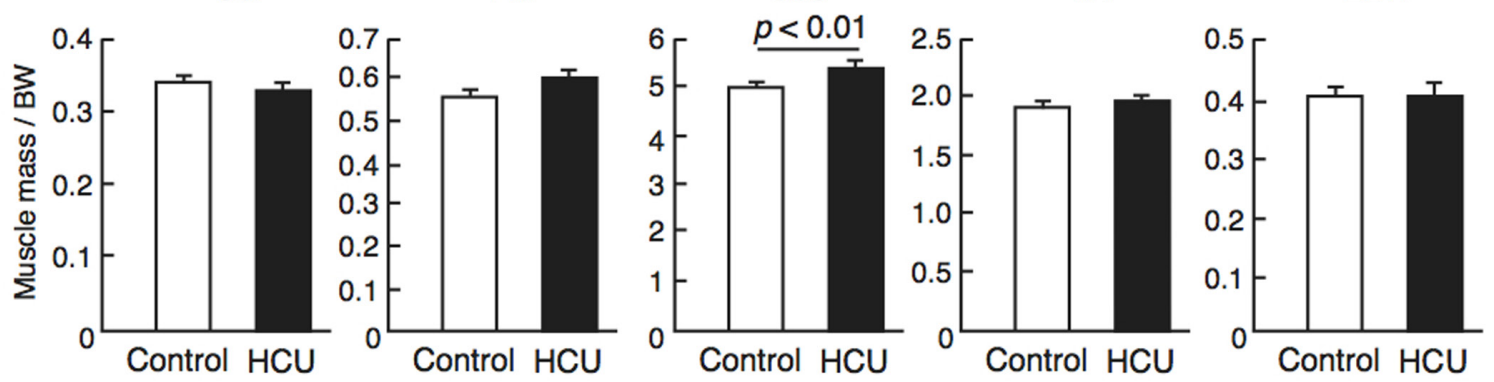

B

BA-D5/Laminin
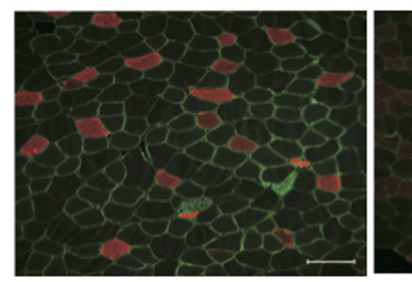

$\mathrm{D}$

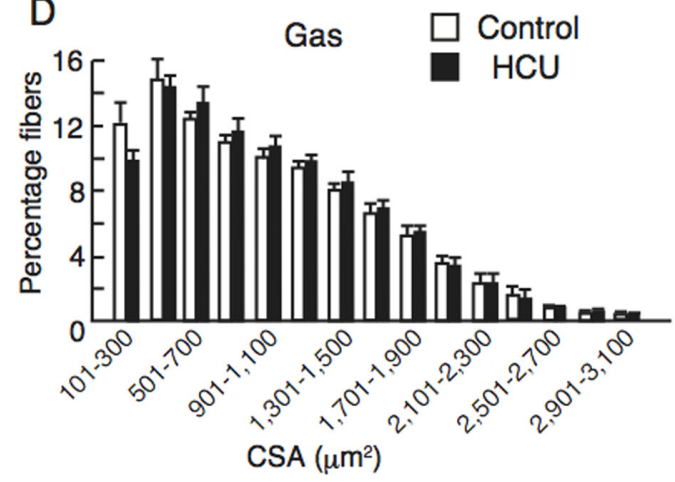

SC-71/Laminin
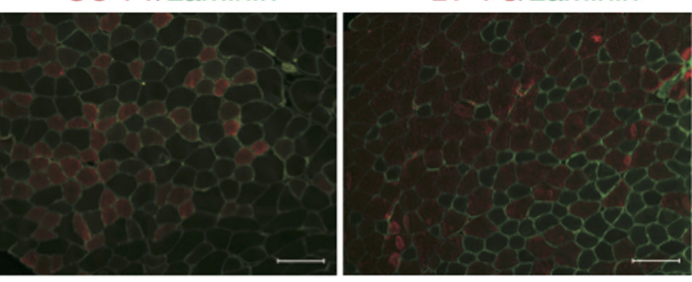

C

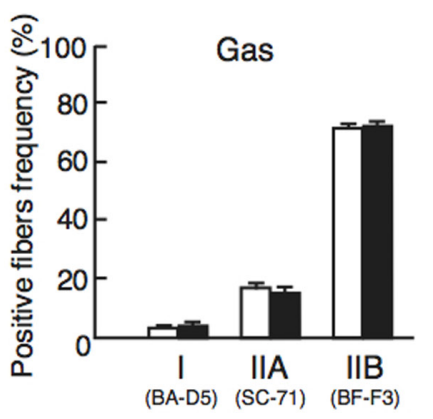

E

$\operatorname{lgf}-1$

Trim63/Murf-1 Fbxo32/Atrogin-1

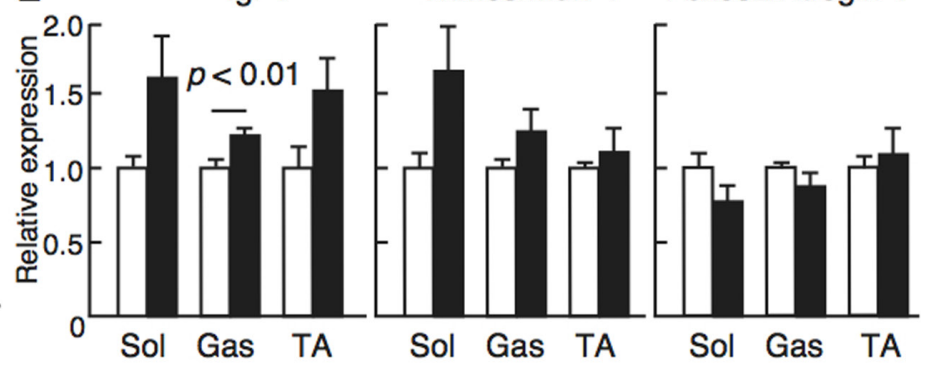

Fig. 3. Characterization of hindlimb skeletal muscles

(A) Weights of five hindlimb muscles from C57BL/6J mice housed in control cages and the HCU are normalized to body weight. Soleus (Sol), plantaris (Pla), gastrocnemius (Gas), tibialis anterior (TA), and extensor digitorum longus (EDL). (B) Immunohistochemical staining for myosin heavy chains using BA-D5 (Type I), SC-71 (Type IIA), and BF-F3 (Type IIB) antibodies, and co-stained with anit-laminin- $\alpha 2$ antibody. Bar, $100 \mu \mathrm{m}$. (C) Percentage of respective fiber types in Gas. Immunoreactive fibers were counted and then calculated as a percentage of the total number of fibers based on the results of (B). (D) Distribution of the cross-sectional areas (CSAs) of gastrocnemius muscle fibers in the control and HCU groups plotted as frequency histograms. (E) Expression analysis of genes controlling muscle mass in hindlimb muscles using real-time PCR. The expression levels of each transcript were normalized to that of the Tbp (TATA box binding protein) transcript. All data in Fig. 3 are represented as means \pm SEM. Control; $\mathrm{n}=6, \mathrm{HCU} ; \mathrm{n}=6$. Open bars indicate the control group. Closed bars indicate the HCU group.

sults suggest that HCU housing has little effect in changing the tissue structure of the heart and kidney.

\section{Characterization of hindlimb muscles}

Skeletal muscle is a classical organ susceptible to gravity, leading to pathogenesis including muscle atrophy. One of the main subjects of mouse space study is therefore to define the mechanism of such condition to prevent muscle atrophy of astronauts unloading from spaceflight, where analysis of muscle behavior in space is necessary [21, 23]. Examination to assess the usefulness of the HCU on muscle study showed that the gastrocnemius weight in the HCU mice were slightly but significantly increased relative to the control group (Fig. 

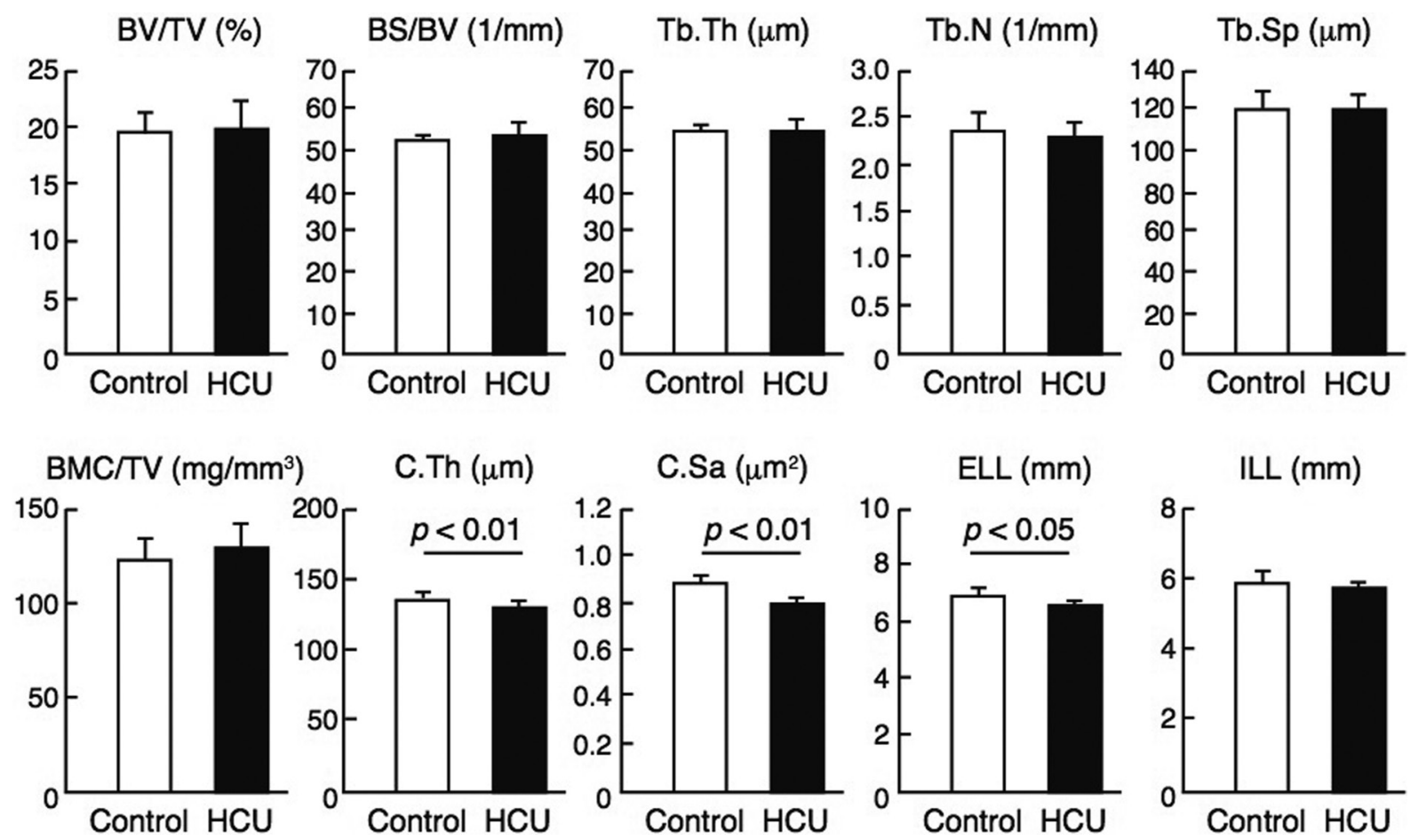

Fig. 4. MicroCT analysis of the femur

The bone volume and structures of the femur were analyzed and quantified. BV/TV: bone volume/tissue volume in trabecular bone; BS/BV: bone surface/bone volume in trabecular bone; Tb.Th: trabecular bone thickness; Tb.N: trabecular bone number; Tb.Sp: trabecular separation; BMC/TV: bone mineral content/tissue volume; C.Th: cortical bone thickness; C.Sa: cortical bone sectional area; ELL: external line length of cortical bone; ILL: internal line length of cortical bone.

3A). The weights of four other hindlimb skeletal muscles in the HCU mice were normal compared to the control mice. To elucidate the mechanism of gastrocnemius muscle hypertrophy in the HCU mice, fiber-type transitions and more cross-sectional areas (CSA) were verified by immunohistochemical analysis. Fiber-type-specific antibodies (BA-D5, SC-71 and BF-F3) were used for staining, with immune reactive fibers being counted (Fig. 3B). The lack of differences in fiber compositions between the mice groups suggests no occurrence of fibertype transitions (Fig. 3C). The frequency distribution of CSAs from the staining of gastrocnemius muscle fiber with the anti-laminin $\alpha 2$ antibody was plotted (Fig. 3D). Plotting the CSAs revealed a slight but insignificant increase of whole fiber CSA distributions of the HCU mice as compared with those of the control mice. To determine the relation between gene expression and muscle hypertrophy, we performed RT-PCR to quantify transcripts in the gastrocnemius, soleus, and tibialis anterior muscles (Fig. 3E). Insulin-like growth factor 1 (Igf-1) is the protein growth factor that promotes protein synthesis and subsequent skeletal muscle hypertrophy [4]. Trim63/Murf-1 and Fbxo32/Atrogin-1 are musclespecific atrophy-related ubiquitin ligases responsible for increased protein degradation through the ubiquitinproteasome system [29]. The expression of Igf-1 in the gastrocnemius muscle significantly increased in the $\mathrm{HCU}$ mice, but not in the other two muscles. The levels of Trim63/Murf-1 and Fbxo32/Atrogin-1 transcripts in the HCU mice were similar to those of the control mice in all three muscles. It is hypothesized that the increase in Igf- 1 expression affected the small increase in gastrocnemius weight, where the precise mechanism is only speculated, such as changes in the posture of HCU mice. These results demonstrated that changes in gastrocnemius characteristics must be considered for future studies.

\section{Microstructural analysis of bone}

Bone homeostasis is regulated by many external systems as well as the endocrine, immune, and central nervous systems. It has been well known that mechanical unloading such as microgravity and bed rest results in 

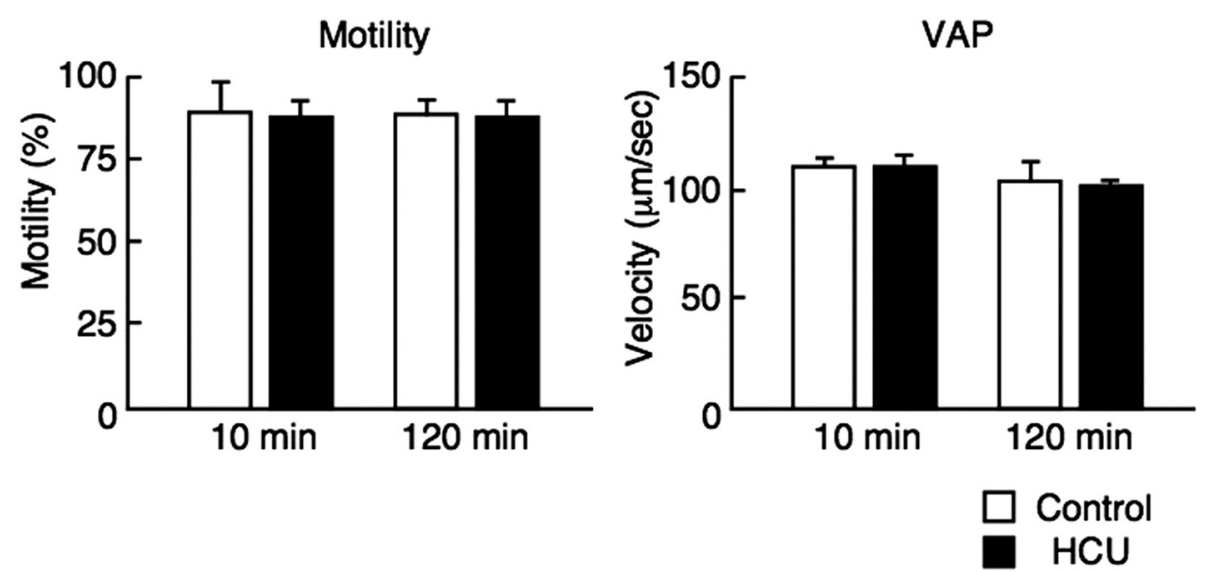

Fig. 5. Cauda epididymal sperm motility

Percentage of spermatozoa motility and average path velocity (VAP) in the control mice and HCU mice at 10 and 120 min. after thawing. Data are represented as means \pm SD. Control; $n=6, H C U$; $\mathrm{n}=6$. Open bars indicate the control group. Closed bars indicate the HCU group.

bone loss, which leads to changes in calcium homeostasis [26]. Bone loss during spaceflight is a serious problem in astromedicine, essentially requiring the development of strategies to protect bone tissues. Thus, it is very important to understand the mechanisms by which microgravity induces bone loss. In this study, the bone mass and structure of the femur - one of the bones most susceptible to microgravity - was evaluated based on microcomputed tomography (microCT) analysis (Fig. 4). The bone volume and structures in trabecular bone did not change between the control mice and HCU mice. The bone mineral content in the HCU mice was also normal compared to the control mice. In contrast, the thickness and sectional area of cortical bone in the $\mathrm{HCU}$ group were significantly reduced $(-4.6 \%$ and $-8.9 \%$, respectively) due to decreased external line length $(-5.1 \%)$, which is apparently attributed to a single housing in a narrow space [18]. Although the bone loss observed in the HCU group is slight compared to that of the mechanical unloading model [25] the cortical bone of the HCU mice should be carefully evaluated.

\section{Male reproductive system}

Many studies have reported on the effect of weightlessness on the reproductive system using ground-based low gravity experiments. For example, the hindlimb suspension test on rodents caused reductions in testicular weight and sperm motility $[12,28]$. It is very important to produce and evaluate the next generations from mice housed in space. In this study, the weight of the testis and epididymis showed no difference between the control mice and HCU mice (Supplementary Table 2). In order to assess the effect of HCU housing on sperm motility, sperm in the epididymis was collected and stored in liquid nitrogen, so that sperm motility and velocity could be evaluated later by using the frozenthawed sperm. Sperm morphology, motility, and velocity showed no difference between the control mice and HCU mice (data not shown, Fig. 5). These findings suggest that housing mice in the HCU does not affect the male reproductive function.

\section{Gene expression pattern}

A mouse genome-wide transcriptional profiling study is planned for the future. Therefore, the transcription abnormalities caused by housing conditions in the HCU should be minimized. The expression of 51 transcripts in ten organs was comprehensively measured by quantitative RT-PCR and summarized in Table 2, except for that of skeletal muscle. Brain-derived neurotrophic factor (BDNF) is linked to various aspects of synaptic plasticity, including the stress-induced plasticity of amygdala. GRIA1 is a subunit of the AMPA receptor (an ionotropic glutamate receptor) and involved in synaptic plasticity [14]. The expression of $B d n f$ in amygdara and Grial in the striatum and cerebellar vermis was unchanged in the HCU mice. In two endocrine organs including the pituitary gland and adrenal gland, the expression level of most genes did not change except for the Calca gene in the thyroid gland. Calca might be up- 
Table 2. Quantitative analysis of gene expression

\begin{tabular}{|c|c|c|}
\hline Gene symbol & Description & Fold-change (SEM) \\
\hline \multicolumn{3}{|l|}{$<$ Amygdala $>$} \\
\hline$B d n f$ & BDNF, Brain derived neurotrophic factor & $1.26(0.49)$ \\
\hline \multicolumn{3}{|l|}{$<$ Striatum $>$} \\
\hline Grial & Gutamate receptor, ionotropic, AMPA1 (alpha 1) & $1.31(0.22)$ \\
\hline \multicolumn{3}{|c|}{$<$ Cerebellar vermis $>$} \\
\hline Grial & Gutamate receptor, ionotropic, AMPA1 (alpha 1) & $1.13(0.17)$ \\
\hline \multicolumn{3}{|l|}{$<$ Pituitary gland $>$} \\
\hline Fshb & Follicle stimulating hormone, beta & $1.43(0.13)$ \\
\hline Gh & Growth hormone & $0.92(0.03)$ \\
\hline$L h b$ & Luteinizing hormone beta polypeptide & $0.74(0.11)$ \\
\hline Pomc & Pro-opiomelanocortin-alpha (ACTH) & $1.04(0.56)$ \\
\hline$T s h b$ & Thyroid stimulating hormone, beta & $0.91(0.17)$ \\
\hline \multicolumn{3}{|l|}{$<$ Adrenal gland $>$} \\
\hline Cypllal & Cytochrome P450, family 11 , subfamily a, polypeptide 1 & $0.90(0.03)$ \\
\hline Cyp $11 b 2$ & Cytochrome P450, family 11 , subfamily B, polypeptide 2 & $0.85(0.04)$ \\
\hline Cyp17a1 & Cytochrome P450, family 17 , subfamily a, polypeptide 1 & $0.87(0.18)$ \\
\hline Cyp21a1 & Cytochrome P450, family 21 , subfamily a, polypeptide 1 & $0.82(0.04)$ \\
\hline$H s d 3 b 1$ & Hydroxy-delta-5-steroid dehydrogenase, 3 beta- and steroid delta-isomerase 1 & $0.84(0.06)$ \\
\hline \multicolumn{3}{|l|}{$<$ Thyroid gland $>$} \\
\hline Calca & Calcitonin-related polypeptide alpha & $1.52(0.10)^{*}$ \\
\hline $\operatorname{Tg}$ & Thyroglobulin & $1.20(0.14)$ \\
\hline \multicolumn{3}{|l|}{$<$ BAT $>$} \\
\hline Cidea-1 & Cell death-inducing DFFA-like effector a & $0.78(0.16)$ \\
\hline Dio-2 & Deiodinase, iodothyronine, type II & $0.20(0.03)^{*}$ \\
\hline Pgcl-a & Peroxisome proliferator-activated receptor gamma, coactivator 1 alpha & $0.45(0.07)^{*}$ \\
\hline Ucp-1 & Uncoupling 1 & $0.45(0.06)^{*}$ \\
\hline$U c p-2$ & Uncoupling 2 & $0.84(0.05)$ \\
\hline \multicolumn{3}{|l|}{$<$ WAT $>$} \\
\hline Adipoq & Adiponectin & $1.06(0.10)$ \\
\hline Lep & Leptin & $0.61(0.06)$ \\
\hline Rbp4 & Retinol binding protein 4 , plasma & $1.00(0.07)$ \\
\hline Retn & Resistin & $0.93(0.13)$ \\
\hline \multicolumn{3}{|l|}{$<$ Heart $>$} \\
\hline Ppargcla & Peroxisome proliferative activated receptor, gamma, coactivator 1 alpha & $0.60(0.08)$ \\
\hline Myh6 & Myosin, heavy polypeptide 6 , cardiac muscle, alpha & $0.60(0.05)$ \\
\hline Myh7 & Myosin, heavy polypeptide 7 , cardiac muscle, beta & $0.87(0.19)$ \\
\hline Tnni3 & Troponin I, cardiac 3 & $1.13(0.04)$ \\
\hline Des & Desmin & $1.04(0.11)$ \\
\hline Colla1 & Collagen, type I, alpha 1 & $0.83(0.07)$ \\
\hline Nppa & Natriuretic peptide type A & $1.01(0.22)$ \\
\hline Nppb & Natriuretic peptide type B & $4.30(1.21)$ \\
\hline Atp2a2 & ATPase, $\mathrm{Ca}++$ transporting, cardiac muscle, slow twitch 2 & $0.73(0.06)$ \\
\hline Fbxo32 & F-box protein 32 & $0.71(0.07)$ \\
\hline Trim63 & Tripartite motif-containing 63 & $0.61(0.08)$ \\
\hline Becn1 & Beclin 1 , autophagy related & $0.69(0.13)$ \\
\hline Gabarapl1 & Gamma-aminobutyric acid A receptor-associated protein-like 1 & $0.87(0.15)$ \\
\hline \multicolumn{3}{|l|}{$<$ Kidney $>$} \\
\hline Ccl2 & Chemokine (C-C motif) ligand 2 & $4.37(0.69)$ \\
\hline$I l 1 b$ & Interleukin 1 beta & $2.16(0.68)$ \\
\hline Il6 & Interleukin 6 & $1.16(0.07)$ \\
\hline $\operatorname{Tnf}$ & Tumor necrosis factor & $0.85(0.05)$ \\
\hline$T g f b 1$ & Transforming growth factor, beta 1 & $0.94(0.10)$ \\
\hline Colla1 & Collagen, type I, alpha 1 & $0.91(0.26)$ \\
\hline Timpl & Tissue inhibitor of metalloproteinase 1 & $1.00(0.08)$ \\
\hline Vcam1 & Vascular cell adhesion molecule 1 & $1.34(0.21)$ \\
\hline Icaml & Intercellular adhesion molecule 1 & $1.18(0.21)$ \\
\hline Scnn1a & Sodium channel, nonvoltage-gated 1 alpha & $1.40(0.16)$ \\
\hline Len 2 & Lipocalin 2 & $1.05(0.04)$ \\
\hline Nphs2 & Nephrosis 2 & $2.06(0.38)$ \\
\hline Nphs1 & Nephrosis 1 & $1.32(0.19)$ \\
\hline Tjp1 & Tight junction protein 1 & $1.32(0.31)$ \\
\hline
\end{tabular}

Fold-change relative to control, Asterisks denote $P<0.05$. 
regulated by the reduction of bone mass to maintain the homeostasis of the blood calcium level. Expression of stress responsive genes, (Pomp in pituitary gland, $C y$ p11a1, Cyp11b2, and Cyp17al in adrenal gland [10]) showed no change in the HCU mice, indicating that the HCU did not cause stress to housing mice. While no change was observed in white adipose tissue, the expression of thermogenesis-related genes (Dio-2, Pgcl-a, and $U c p-1)$ was statistically decreased in brown adipose tissue of the HCU mice. As the increase in expression of thermogenesis-related genes in response to exercise is a well-known theory [22] the reduced physical movement of the HCU mice has been suggested as a possible cause of the downregulation of these genes. In the heart, the expression level of most genes related to the cytoskeleton, cardiac injury, cardiac atrophy, and autophagy did not change much as compared to that of the control mice. In the kidney, most of the genes related to inflammation, fibrosis, endothelial dysfunction, regulation of the renal function, and glomerular structure showed no significant change. These results revealed that most gene expression did not change or changed slightly, which must be carefully considered relative to using the HCU.

Space experiments using mice require specially designed habitats applicable for the space environment, thus causing slight but diverse differences in the conditions of housed mice. In this study, we showed that the HCU for installation in the CBEF causes no biological abnormalities on mice, though slight but significant changes were identified in several organs. Thus, we conclude that the HCU is applicable for future space mouse experiments using the $\mathrm{CBEF}$, but these characteristic features of the HCU must be considered, followed by using the homologous HCU for control and sample groups, to find the true effects of spaceflight and microgravity. The HCU installed in the CBEF will be vital to permit comprehensive space experimental analysis on male mice in the future.

\section{Acknowledgments}

We wish to thank Mitsubishi Heavy Industries, Ltd. for manufacturing the HCU hardware. We would also like to thank Ms. Akane Yumoto of JAXA and Ms. Hiromi Suzuki of the Japan Space Forum for coordinating the study, and Ms. Naoko Murakami and Ms. Rika Oshima of Advanced Engineering Services Co., Ltd. for their assistance in animal care. This study was conduct- ed as a part of the prioritized research selected for life sciences commissioned by the Japan Aerospace Exploration Agency (14YPTK-005512).

\section{References}

1. Akiyama, N., Shinzawa, M., Miyauchi, M., Yanai, H., Tateishi, R., Shimo, Y., Ohshima, D., Matsuo, K., Sasaki, I., Hoshino, K., Wu, G., Yagi, S., Inoue, J., Kaisho, T., and Akiyama, T. 2014. Limitation of immune tolerance-inducing thymic epithelial cell development by Spi-B-mediated negative feedback regulation. J. Exp. Med. 211: 2425-2438. [Medline] [CrossRef]

2. Cancedda, R., Liu, Y., Ruggiu, A., Tavella, S., Biticchi, R., Santucci, D., Schwartz, S., Ciparelli, P., Falcetti, G., Tenconi, C., Cotronei, V., and Pignataro, S. 2012. The Mice Drawer System (MDS) experiment and the space endurance recordbreaking mice. PLoS ONE 7: e32243. [Medline] [CrossRef]

3. Congdon, C.C., Allebban, Z., Gibson, L.A., Kaplansky, A., Strickland, K.M., Jago, T.L., Johnson, D.L., Lange, R.D., and Ichiki, A.T. 1996. Lymphatic tissue changes in rats flown on Spacelab Life Sciences-2. J. Appl. Physiol. 81: 172-177. [Medline]

4. DeVol, D.L., Rotwein, P., Sadow, J.L., Novakofski, J., and Bechtel, P.J. 1990. Activation of insulin-like growth factor gene expression during work-induced skeletal muscle growth. Am. J. Physiol. 259: E89-E95. [Medline]

5. Everds, N.E., Snyder, P.W., Bailey, K.L., Bolon, B., Creasy, D.M., Foley, G.L., Rosol, T.J., and Sellers, T. 2013. Interpreting stress responses during routine toxicity studies: a review of the biology, impact, and assessment. Toxicol. Pathol. 41: 560-614. [Medline] [CrossRef]

6. Fullwood, S., Hicks, T.A., Brown, J.C., Norman, R.L., and McGlone, J.J. 1998. Floor space needs for laboratory mice: C56BL/6 males in solid-bottom cages with bedding. ILAR J. 39: 29-36. [Medline] [CrossRef]

7. Gridley, D.S., Pecaut, M.J., Green, L.M., Miller, G.M., and Nelson, G.A. 2002. Hypergravity-induced immunomodulation in a rodent model: lymphocytes and lymphoid organs. $J$. Gravit. Physiol. 9: 15-27. [Medline]

8. Gruver, A.L. and Sempowski, G.D. 2008. Cytokines, leptin, and stress-induced thymic atrophy. J. Leukoc. Biol. 84: 915923. [Medline] [CrossRef]

9. Hamada, J., Baasanjav, A., Ono, N., Murata, K., Kako, K., Ishida, J., and Fukamizu, A. 2015. Possible involvement of downregulation of the apelin-APJ system in doxorubicininduced cardiotoxicity. Am. J. Physiol. Heart Circ. Physiol. 308: H931-H941. [Medline] [CrossRef]

10. Harvey, P.W. 2014. Adrenocortical endocrine disruption. J. Steroid. Biochem. Mol. Biol. S0960-0760(14)00244-1.

11. Ito, N., Ruegg, U.T., Kudo, A., Miyagoe-Suzuki, Y., and Takeda, S. 2013. Activation of calcium signaling through Trpv1 by nNOS and peroxynitrite as a key trigger of skeletal muscle hypertrophy. Nat. Med. 19: 101-106. [Medline] [CrossRef]

12. Kamiya, H., Sasaki, S., Ikeuchi, T., Umemoto, Y., Tatsura, H., Hayashi, Y., Kaneko, S., and Kohri, K. 2003. Effect of 
simulated microgravity on testosterone and sperm motility in mice. J. Androl. 24: 885-890. [Medline] [CrossRef]

13. Kostin, S., Rieger, M., Dammer, S., Hein, S., Richter, M., Klövekorn, W.P., Bauer, E.P., and Schaper, J. 2003. Gap junction remodeling and altered connexin43 expression in the failing human heart. Mol. Cell. Biochem. 242: 135-144. [Medline] [CrossRef]

14. Lu, B., Nagappan, G., and Lu, Y. 2014. BDNF and synaptic plasticity, cognitive function, and dysfunction. Handbook Exp. Pharmacol. 220: 223-250. [Medline] [CrossRef]

15. Mao, X.W., Pecaut, M.J., Stodieck, L.S., Ferguson, V.L., Bateman, T.A., Bouxsein, M.L., and Gridley, D.S. 2014. Biological and metabolic response in STS-135 space-flown mouse skin. Free Radic. Res. 48: 890-897. [Medline] [CrossRef]

16. Morey-Holton, E.R., Halloran, B.P., Garetto, L.P., and Doty, S.B. 2000. Animal housing influences the response of bone to spaceflight in juvenile rats. J. Appl. Physiol. 88: 13031309. [Medline]

17. Morita, H., Obata, K., Abe, C., Shiba, D., Shirakawa, M., Kudo, T., and Takahashi, S. 2015. Feasibility of a short-arm centrifuge for mouse hypergravity experiments. PLOS ONE 10: e0133981. [Medline] [CrossRef]

18. Nagy, T.R., Krzywanski, D., Li, J., Meleth, S., and Desmond, R. 2002. Effect of group vs. single housing on phenotypic variance in C57BL/6J mice. Obes. Res. 10: 412-415. [Medline] [CrossRef]

19. Nojima, T., Haniuda, K., Moutai, T., Matsudaira, M., Mizokawa, S., Shiratori, I., Azuma, T., and Kitamura, D. 2011. In-vitro derived germinal centre B cells differentially generate memory B or plasma cells in vivo. Nat. Commun. 2: 465. [Medline] [CrossRef]

20. Novoselova, E.G., Lunin, S.M., Khrenov, M.O., Parfenyuk, S.B., Novoselova, T.V., Shenkman, B.S., and Fesenko, E.E. 2015. Changes in immune cell signalling, apoptosis and stress response functions in mice returned from the BIONM1 mission in space. Immunobiology 220: 500-509. [Medline] [CrossRef]

21. Ogneva, I.V., Maximova, M.V., and Larina, I.M. 2014. Structure of cortical cytoskeleton in fibers of mouse muscle cells after being exposed to a 30-day space flight on board the BION-M1 biosatellite. J. Appl. Physiol. 116: 1315-1323. [Medline] [CrossRef]

22. Sanchez-Delgado, G., Martinez-Tellez, B., Olza, J., Aguilera, C.M., Gil, Á., and Ruiz, J.R. 2015. Role of Exercise in the Activation of Brown Adipose Tissue. Ann. Nutr. Metab. 67: 21-32. [Medline] [CrossRef]
23. Sandonà, D., Desaphy, J.F., Camerino, G.M., Bianchini, E., Ciciliot, S., Danieli-Betto, D., Dobrowolny, G., Furlan, S., Germinario, E., Goto, K., Gutsmann, M., Kawano, F., Nakai, N., Ohira, T., Ohno, Y., Picard, A., Salanova, M., Schiffl, G., Blottner, D., Musarò, A., Ohira, Y., Betto, R., Conte, D., and Schiaffino, S. 2012. Adaptation of mouse skeletal muscle to long-term microgravity in the MDS mission. PLOS ONE 7: e33232. [Medline] [CrossRef]

24. Shinohara, M., Nakamura, M., Masuda, H., Hirose, J., Kadono, Y., Iwasawa, M., Nagase, Y., Ueki, K., Kadowaki, T., Sasaki, T., Kato, S., Nakamura, H., Tanaka, S., and Takayanagi, H. 2012. Class IA phosphatidylinositol 3-kinase regulates osteoclastic bone resorption through protein kinase B-mediated vesicle transport. J. Bone Miner. Res. 27: 2464-2475. [Medline] [CrossRef]

25. Simske, S.J., Guerra, K.M., Greenberg, A.R., and Luttges, M.W. 1992. The physical and mechanical effects of suspension-induced osteopenia on mouse long bones. J. Biomech. 25: 489-499. [Medline] [CrossRef]

26. Smith, S.M., Abrams, S.A., Davis-Street, J.E., Heer, M., O’Brien, K.O., Wastney, M.E., and Zwart, S.R. 2014. Fifty years of human space travel: implications for bone and calcium research. Annu. Rev. Nutr. 34: 377-400. [Medline] [CrossRef]

27. Taguma, K., Nakamura, C., Ozaki, A., Suzuki, C., Hachisu, A., Kobayashi, K., Mochida, K., Ogura, A., Kaneda, H., and Wakana, S. 2009. A practical novel method for ensuring stable capacitation of spermatozoa from cryopreserved C57BL/6J sperm suspension. Exp. Anim. 58: 395-401. [Medline] [CrossRef]

28. Tash, J.S., Johnson, D.C., and Enders, G.C. 2002. Long-term (6-wk) hindlimb suspension inhibits spermatogenesis in adult male rats. J. Appl. Physiol. 92: 1191-1198. [Medline] [CrossRef]

29. Vinciguerra, M., Musaro, A., and Rosenthal, N. 2010. Regulation of muscle atrophy in aging and disease. $A d v$. Exp. Med. Biol. 694: 211-233. [Medline] [CrossRef]

30. Yano, S., Masuda, D., Kasahara, H., Omori, K., Higashibata, A., Asashima, M., Ohnishi, T., Yatagai, F., Kamisaka, S., Furusawa, T., Higashitani, A., Majima, J.H., Nikawa, T., Wakabayashi, K., Takahashi, H., Suzuki, H., Shimazu, T., Fukui, K., Hattori, A., Tanigaki, F., Shirakawa, M., Nakamura, T., Yoshimura, Y., Suzuki, N., and Ishioka, N. 2012. Excellent thermal control ability of cell biology experiment facility (CBEF) for ground-based experiments and experiments onboard the Kibo Japanese Experimental Module of International Space Station. Biol. Sci. Space 26: 12-20. [CrossRef] 